\title{
Materiais manipuláveis e engajamento de estudantes nas aulas de matemática envolvendo tópicos de geometria
}

\author{
Manipulable materials and engagement of students \\ in math classes involving topics of geometry
}

Jamerson dos Santos Pereira ${ }^{1}$. Andreia Maria Pereira de Oliveira ${ }^{2}$

\begin{abstract}
Resumo: Neste artigo, analisamos o engajamento mútuo de estudantes em aulas de Matemática que abordaram tópicos de geometria, fazendo uso de materiais manipuláveis. Para compreender o objeto de estudo, utilizamos a perspectiva da aprendizagem situada segundo Jean Lave e Etienne Wenger. Os dados foram coletados primariamente por meio da observação, mas também foram utilizados entrevista e documentos (registros dos estudantes) para ampliar os dados e subsidiar interpretações. Os resultados sugerem que o conhecimento da prática é mutável segundo as mudanças que ocorrem nas formas de engajamento. Estas formas são específicas e caracterizam outros engajamentos mais amplos. As seguintes situações de engajamentos foram caracterizadas: o engajamento de estudantes no contato preliminar com os elementos do material manipulável; o envolvimento de estudantes no recorte dos quadrados conforme as regras; o engajamento na associação do ângulo nulo à posição inicial dos palitos; o envolvimento na associação dos lados dos quadrados com os lados do triângulo.
\end{abstract}

Palavras-chave: Ensino de matemática. Ensino de geometria. Material manipulável. Engajamento.

\begin{abstract}
In this paper, we analyze the mutual engagement of students in the development of mathematics lessons that addressed topics of geometry, in which manipulative materials were used. To understand the object of study, we used the Situated Learning Perspective according to Jean Lave and Etienne Wenger. Data were collected through observation, interviews and documents (student records during the tasks). The results suggest that the practical knowledge is changeable according to changes occurring in the forms of engagement, and featuring other broader engagement. Furthermore, we presented the following situational engagements: the engagement of students in primary contact with the elements of manipulative materials, the involvement of students cutting out squares according to the rules given, the association of engagement in a zero angle to the starting position of the sticks, and the involvement in the association with the sides of the square and the sides of the triangle.
\end{abstract}

Keywords: Mathematics teaching. Geometry teaching. Manipulative material. Engagement.

\footnotetext{
${ }^{1}$ Universidade Federal do Recôncavo da Bahia (UFRB), Centro de Formação de Professores, Amargosa, BA, Brasil. E-mail: <pereirajamerson@hotmail.com>

${ }^{2}$ Universidade Federal da Bahia (UFBA), Faculdade de Educação, Salvador, BA, Brasil.
} 


\section{Introdução}

O uso de materiais didáticos que são especialmente concebidos para fins da educação, tais como livros didáticos, jogos matemáticos e materiais concretos, tem sido tema de discussão de pesquisas em Educação Matemática (CLEMENTS, 1999; PAIS, 2000; LORENZATO, 2006). Tais autores apontam que, de alguma maneira, deve haver uma reflexão sobre sua utilização. Nesse sentido, concordamos com Pais (2000) quando ele argumenta que se corre o risco de recair em um empirismo que não contribui para a construção dos aspectos racional e abstrato que são inerentes ao ensino de geometria.

Assim como Moyer (2001), Clements (1999) chama atenção para o fato de que os materiais didáticos por si só não garantem sucesso do estudante, mas ele acredita que estudantes que fazem uso deles nas aulas de Matemática, geralmente, superam os que não usam, mesmo que sejam pequenas as superações. Lorenzato (2006) refere-se aos materiais didáticos manipuláveis ou concretos, muitas vezes, como materiais manipuláveis apenas. De modo semelhante, utilizaremos a expressão materiais manipuláveis ${ }^{3}$ compreendendo-os como elementos capazes de estabelecer alguma relação entre os objetivos do ensino da Matemática e os resultados (GELLERT, 2004). Porém, é preciso frisar que a ideia que temos é mais abrangente do que considerar os manipuláveis como artefatos que são utilizados na aula de matemática para desenvolver tarefas também matemáticas.

Consoante a esse aspecto, os materiais manipuláveis não se restringem às aulas de Matemática, muito embora alguns deles se adéquem melhor a tais aulas. Diante disso, assumimos a definição de Reys (1971 apud NACARATO, 2005, p. 3), que aponta os materiais manipuláveis como "objetos ou coisas que o estudante é capaz de sentir, tocar, manipular e movimentar. Podem ser objetos reais que têm aplicação no dia-a-dia ou podem ser objetos que são usados para representar uma idéia". Deste modo, consideramos manipulável qualquer objeto que venha a compor o material, que pode ser sentido em sua totalidade, no intuito de cumprir o objetivo das tarefas que serão apresentadas a seguir.

Nesse sentido, o que entendemos por materiais manipuláveis não descarta uma folha de papel, uma régua, uma tesoura, pois, apesar de eles não serem necessariamente utilizados para trabalhar ideias matemáticas, podem ser usados pelos estudantes para realizarem alguma manipulação que favoreça a elaboração de conjecturas ou ideias sobre um tópico da Matemática. Desse modo, o material manipulável pode ser uma ferramenta interessante para promover a aprendizagem, uma vez que permite a manutenção de um momento grupal, no qual alguns estudantes podem interagir, trocar informações, gestos e modos de falar e agir sobre determinadas situações, a partir dos materiais manipuláveis. Assim, em consonância com a perspectiva da aprendizagem situada ${ }^{4}$ segundo Lave e Wenger (1991), o aprender mencionado pode ser diretamente ligado à prática social, sendo que a aprendizagem toma forma sem desprezar, naturalmente, o que historicamente foi estabelecido.

\footnotetext{
${ }^{3}$ Para evitar repetições textuais, utilizaremos as expressões materiais manipuláveis, materiais e manipuláveis para nos referirmos aos materiais manipuláveis tal como compreende Reys (1971 apud NACARATO, 2005, p. 3).

${ }^{4} \mathrm{Na}$ próxima seção, discutiremos alguns conceitos desta perspectiva.
} 
É importante ressaltar, entretanto, que os materiais manipuláveis não são garantidores de nenhuma prática pedagógica que garanta aprendizagem. Moyer (2001) discute que alguns professores utilizaram materiais manipuláveis meramente para entretenimento dos estudantes. Esse é apenas um dos modos de "ver" os materiais manipuláveis, e que contraria nossa visão. Em contrapartida, por exemplo, podemos citar o estudo de Souza e Barbosa (2010), no qual os materiais manipuláveis não tiveram foco no entretenimento, mas ensejaram a constituição de práticas questionadoras ${ }^{5}$, por conta do contexto da pesquisa.

Ainda nessa direção, podemos afirmar que os materiais manipuláveis não possuem significados em si mesmos (MOYER, 2001). Desse modo, entendemos o contexto como proporcionador de inúmeros significados. Tudo vai depender de como as interações entre os sujeitos e os materiais vão se desenrolar no contexto social ${ }^{6}$. Sobre isso é importante nos questionarmos: como estudantes engajam-se na utilização de materiais manipuláveis nas aulas de Matemática?

Nesse sentido, a matemática não existe nos materiais manipuláveis e seu valor depende de como eles são utilizados pelos sujeitos para "resolver" as questões que lhes são propostas. Tal compreensão parece aceitável no sentido de que os materiais manipuláveis não precisam ser necessariamente pensados ou destinados a algum conteúdo matemático. Ou seja, eles podem ser utilizados com outras finalidades. No entanto, se o destino do material for algo relacionado com a matemática, este recurso deve ser inserido com muita atenção pelo professor, para que se consigam atingir os objetivos traçados para a utilização do material, conforme o conteúdo a ser explorado.

Diante disso, focaremos a discussão sobre os materiais manipuláveis no contexto da prática social de estudantes em aulas de Matemática, nas quais foram abordados dois tópicos de geometria: ângulos fundamentais no círculo e teorema de Pitágoras. Portanto, analisaremos como esses estudantes se engajaram nas aulas, observando como se dão as formas de engajamento e as caracterizando. Nas próximas seções, traremos: a fundamentação teórica, o método e o contexto desta pesquisa, bem como a discussão dos dados e conclusões.

\section{Prática social, participação e engajamento mútuo}

Primeiramente, é preciso deixar claro que descrever participação em termos utilizados por Lave e Wenger (1991) não nos permite atrelar esse fenômeno a uma ideia de temporalidade ou localidade. Não é possível conceber a participação se dando em um determinado local ou espaço temporal unicamente. A compreensão de participação abrange mais que isso, diz respeito a ser participante ativo nas práticas sociais de um grupo (WENGER, 1998). Assim, na medida em que os sujeitos vão se apropriando dos costumes e ações corriqueiras da prática de um determinado grupo, eles vão apresentando formas diferentes de participação. Para participar de uma prática social, não é preciso, necessariamente, estar presente, até porque as diversas interações promovidas no âmbito da prática social não fazem nenhuma referência aos limites físicos da comunidade, ou seja, não há limites fronteiriços para a prática social.

\footnotetext{
${ }^{5}$ Segundo os autores, práticas questionadoras referem-se às práticas em que estudantes questionam o fabricante dos materiais manipuláveis ou, mesmo, as compreensões do professor.

${ }^{6}$ Tal expressão será definida na próxima seção.
} 
Portanto, na prática social, a participação se dá num envolvente sistema de atividades ou tarefas desempenhadas pelos membros. Nesse movimento de participação, pode ser considerada a partilha do que cada participante compreende sobre aquilo que é realizado ou feito na prática. Assim, o significado que é negociado por eles sobre cada elemento constitutivo da prática (sejam eles: as ações, as falas, os objetos e outros) é, em algum momento, compartilhado.

Segundo Wenger (1998), essa prática social significa um fazer dentro de um contexto histórico e social que dá estrutura e significado às nossas ações. No presente estudo, a prática social em questão é a matemática escolar. Nessa prática, as relações sociais são específicas e, por conta disso, envolvem: linguagem, símbolos, ferramentas ${ }^{7}$, papéis bem definidos, critérios específicos, procedimentos, regulamentos, contratos, percepções específicas, relações implícitas e visões de mundo compartilhadas (WENGER, 1998). As interações entre os estudantes e professores são reguladas pelos procedimentos, regulamentos e pelos papéis destinados aos sujeitos que integram o contexto da sala de aula.

A perspectiva da aprendizagem situada de Lave e Wenger (1998) desloca o eixo de análise dos indivíduos isoladamente para os indivíduos como participantes no/do mundo social. As dicotomias entre mente e corpo, contemplar e envolver-se, abstrair e experimentar não fazem sentido tendo em vista que os autores não delimitam a prática em torno de tais dicotomias. Afinal, tudo está conectado, ou seja, os participantes, o mundo social e as ações estão intimamente ligados ao conhecimento, à aprendizagem na prática e ao discurso oriundo da prática.

$\mathrm{Na}$ dinâmica do grupo social, a participação é pautada na negociação de significados no contexto em que os sujeitos estão inseridos; essas significações não são estáticas, pois permitem uma nova negociação. As compreensões geradas na prática social e as experiências advindas dela possuem significados comuns aos membros, são compartilhados. Entretanto, não queremos gerar a compreensão de que apenas as coisas que estão relacionadas à prática, à qual pertencemos, são significativas. Pelo contrário, queremos frisar que o mundo social é muito maior do que as práticas vivenciadas por cada indivíduo (FRADE, 2003). Assim, podemos observar que os conceitos de concreto e abstrato não fazem referência, necessariamente, a significativo e não significativo, respectivamente, tendo em vista que algo concreto para uns pode ser abstrato para outros, e vice-versa.

O intuito, nesse momento, é destacar alguns elementos que são indissociáveis da prática social e, por consequência, da participação. No entanto, ressaltamos, antes disso, que o foco desta pesquisa é o primeiro dos elementos discutidos a seguir. Wenger (1998) argumenta que existem três relações que associam a prática com a comunidade formada num determinado contexto: (1) O engajamento/envolvimento mútuo (organizado em torno dos objetivos que a comunidade busca alcançar); (2) Um empreendimento conjunto (e, consequentemente, negociação mútua e responsabilidade da qual se deve prestar contas); (3) Um repertório compartilhado (rotinas, linguagens, símbolos, modos de fazer). Tendo em vista a compreensão de alguns conceitos, é preciso delimitar alguns aspectos da teoria.

\footnotetext{
${ }^{7}$ Em consonância com a teoria, ferramentas podem ser concebidas como recursos que são utilizados ou construídos durante a prática social desenvolvida pelos participantes. Seu uso, porém, não é estático e muda conforme a necessidade dos membros. Todavia, como tudo que ocorre na prática, a funcionalidade deste recurso dependerá da aceitação dos membros, isto é, dependerá da legitimação dos membros.
} 
A participação é mais do que o simples engajamento numa tarefa, pelo fato de que nessa há um reconhecimento mútuo (explícito ou implícito). Suponhamos que, nas tarefas que serão descritas a seguir, um dos estudantes observados estivesse lendo uma revista em quadrinhos no momento em que todos estavam manipulando o material utilizado na tarefa proposta pelo professor. Esse estudante estaria engajado na leitura de sua revista, mas não seria reconhecido como uma participante do grupo, por não ser reconhecido como participante da tarefa.

Nesse sentido, engajamento refere-se ao envolvimento ativo em processos de negociação conjunta, ou seja, em que todos contribuem para dar significados àquilo em que estão envolvidos. Assim, podemos considerar os participantes como tais quando reconhecemos seu envolvimento integral e grupal naquilo que se propõem a fazer. Portanto, engajar-se em algo diz respeito ao reconhecimento do que ocorre na situação em sua totalidade.

Por fim, utilizando as lentes da perspectiva da aprendizagem situada (LAVE; WENGER, 1991), uma ocasião na qual os estudantes podem utilizar os materiais manipuláveis na aula de Matemática que abordam tópicos de geometria constitui-se em uma prática social. Neste estudo, os participantes dessa prática, incluindo as professoras, puderam interagir uns com os outros e com os materiais manipuláveis, e, do mesmo modo, puderam dar significado a suas ações, a suas falas, a seus gestos e a suas ferramentas, levando em consideração os significados historicamente já atribuídos. Assim, discutiremos esses aspectos a partir dos trechos das aulas apresentados posteriormente.

\section{Contexto do estudo}

Os dados do estudo apresentados neste artigo foram coletados em duas salas de aula, sendo uma do $8^{\circ}$ ano e outra do $9^{\circ}$ ano, séries finais do Ensino Fundamental, da rede pública de Feira de Santana, BA, Salvador, BA. Foram utilizadas três aulas de cinquenta minutos na turma de $8^{\circ}$ ano da escola de Feira de Santana e duas aulas de cinquenta minutos na turma de $9^{\circ}$ ano da escola de Salvador. As tarefas utilizadas nesse estudo foram desenvolvidas pelo Observatório de Educação Matemática ${ }^{8}$ da Bahia (OEM-Bahia). O grupo do OEM-Bahia é formado por: professores da educação básica, graduandos, pós-graduandos e pesquisadores, com o foco na produção de materiais curriculares educativos ${ }^{9}$ que possibilitem potencializar a aprendizagem dos professores. O grupo produziu tarefas que exploravam tópicos de geometria no ano de 2011 e duas professoras que estavam envolvidas na construção de tarefas com materiais manipuláveis foram convidadas a participar desta pesquisa.

\footnotetext{
${ }^{8}$ O Programa Observatório da Educação, resultado da parceria entre a Coordenação de Aperfeiçoamento de Pessoal de Nível Superior (Capes), o Instituto Nacional de Estudos e Pesquisas Educacionais Anísio Teixeira (INEP) e a Secretaria de Educação Continuada, Alfabetização e Diversidade (Secadi), foi instituído pelo Decreto Presidencial $n^{\circ} 5.803$, de 08 de junho de 2006, com o objetivo de fomentar estudos e pesquisas em educação, que utilizem a infraestrutura disponível das Instituições de Educação Superior (IES) e as bases de dados existentes no INEP, estimulando a produção acadêmica e a formação de recursos pós-graduados, em nível de mestrado e doutorado. Disponível em: <http://portal.inep.gov.br/>. Acesso em: 13 nov. 2015.

${ }^{9}$ Materiais curriculares educativos são os que visam a aprendizagem de estudantes e professores (REMILLARD, 2005).
} 
A professora Ana ${ }^{10}$ é licenciada em Ciências e Matemática, trabalha na rede pública de ensino há 26 anos, desenvolveu uma tarefa que explorava ângulos fundamentais no círculo a partir do uso de materiais manipuláveis. No desenvolvimento da tarefa, os estudantes utilizaram: recorte de papel em formato de círculo, palitos de picolé, taxinhas de ferro, hidrocores e lápis de cor. Ana organizou a turma em grupos de quatro e de cinco estudantes. A escolha do grupo observado foi cedida para a professora, que escolheu livremente. A justificativa dela baseou-se no posicionamento do grupo na sala de aula, o que evitaria que outros estudantes de outros grupos fossem filmados também. Os participantes foram: Camila, Gabriela, Felipe, Gustavo e Marta.

Lúcia, também licenciada em Ciências e Matemática, é professora da rede pública de ensino há 21 anos, desenvolveu uma tarefa que enfatizou as compreensões acerca do teorema de Pitágoras por meio de materiais manipuláveis. O kit do material manipulável constituía-se de: um quadrado amarelo $(3 \times 3 \mathrm{~cm})$, um quadrado vermelho $(4 \times 4 \mathrm{~cm})$, um quadrado azul $(5 \times 5$ $\mathrm{cm})$ e um triângulo retângulo $(3 \mathrm{~cm}, 4 \mathrm{~cm}$ e $5 \mathrm{~cm})$. A professora também organizou a turma em grupos de quatro e de cinco estudantes. O critério utilizado pela professora para a escolha do grupo foi observar aqueles estudantes que se destacavam nas aulas. Raquel, Lucas, Flávia, Fernando e João integraram o grupo observado.

\section{Método do estudo}

Neste estudo, buscamos interpretar o fenômeno participação em termos do engajamento mútuo (LAVE; WENGER, 1991). Em outras palavras, estamos interessados em analisar a vivência de um grupo de estudantes numa sala de aula, em termos das experiências vividas. Assim, esse estudo pautou-se na abordagem de natureza qualitativa, como entendem Denzin e Lincoln (2005). Segundo os autores, o pesquisador qualitativo, nesse caso, vale-se de métodos de pesquisa para produzir seus dados, como entrevistas e observações, e organiza seus dados de modo que possam ser analisados.

Os dados, que podem ser obtidos por meio da observação, dos documentos (registros dos estudantes), da filmagem e das entrevistas - conforme os autores citados - foram obtidos basicamente por meio da observação e dos documentos produzidos pelos estudantes durante o desenvolvimento da tarefa. A observação, que foi operacionalizada por meio da filmagem, propiciou a constatação de comportamentos inconscientes ou não intencionais na aula de Matemática que abordou o tópico de geometria, com a utilização de materiais manipuláveis, o que permitiu capturar o comportamento dos estudantes em determinado momento (ALVES-MAZZOTI, 2002). Além disso, utilizamos as anotações escritas pelo pesquisador durante a aula, as quais foram de fundamental importância para registrar informações sobre: a organização da sala, a organização da tarefa e as contribuições de cada estudante ou da professora.

Em relação aos procedimentos utilizados para analisar os dados, utilizamos os procedimentos analíticos da Grounded theory (CHARMAZ, 2009), os quais sugerem princípios e

\footnotetext{
${ }^{10}$ Pseudônimos foram utilizados para preservar a identidade dos participantes desse estudo.
} 
práticas para análise de processos e elaboração de argumentos baseados nos dados de pesquisa, fomentando, assim, compreensões teóricas. Entretanto, não nos comprometemos com os seus paradigmas. A Grounded theory sugere a análise em níveis, sendo o primeiro deles a codificação, que foi utilizada na primeira etapa da análise. Desse modo, os dados foram transcritos a partir da "leitura" exaustiva dos vídeos e analisados linha a linha (CHARMAZ, 2009). Com isso, foram originados alguns códigos, pequenas frases que resumiam as ações e falas dos estudantes e que caracterizavam o envolvimento e compartilhamento de uma linguagem própria do grupo. Assim, consideramos, por exemplo, que, na fala do estudante "o quadrado é igual à hipotenusa...", o código seria "Reconhecendo a relação dos quadrados com os lados do triângulo retângulo", tendo em vista que o estudante fazia referência a um quadrado que tinha lado igual à hipotenusa do triângulo retângulo.

Em etapa posterior, esses códigos foram agrupados de forma a representar um conjunto de códigos que possuíam propriedades comuns, ou seja, formando categorias que indicam ideias mais gerais. Essas categorias foram apresentadas na forma de episódios, como pode ser vistas mais adiante. Por fim, o olhar transversal impregnado da teoria sobre os resultados da pesquisa, ensejaram possíveis contribuições/compreensões teóricas para discutir a participação no sentido de como estudantes se envolvem quando participam em aulas de Matemática.

\section{Apresentação dos dados}

Nesta seção, os episódios apresentados foram estruturados em torno das falas e ações dos estudantes e das duas professoras, Ana e Lúcia, durante o desenvolvimento de duas tarefas em aulas distintas que abordaram tópicos de geometria, nas quais os estudantes faziam uso de materiais manipuláveis. Além das falas coletadas no processo de observação, foram utilizadas como consulta as entrevistas feitas com os estudantes no final de cada tarefa e os registros (documentos) produzidos por eles. Alguns elementos utilizados na transcrição dos dados foram inspirados nos trabalhos de Silva (2002) e Paula e Sanz Espinar (2002). Cada episódio foi construído a partir do que foi considerado importante na observação e que expressava sugestivamente formas de engajamento, considerando códigos que representavam ideias comuns. Dois episódios de uma tarefa e um episódio de outra tarefa foram apresentados nessa seção, totalizando três episódios para este artigo.

\section{Episódio 1: $O$ engajamento na associação do ângulo nulo com a posição inicial dos palitos}

Neste episódio, foi possível notar o momento em que os estudantes começaram a lidar com o ângulo nulo a partir da rotação de palitos de picolé sobre um círculo com diâmetro de $12 \mathrm{~cm}$. Nesta etapa, os estudantes já procederam a manipulação que dividiu o círculo em quatro partes iguais, formando quatro ângulos de noventa graus. Os estudantes mantiveram os palitos de picolés sobrepostos, de modo que o ângulo entre eles era de zero grau, como pode ser observado na Figura 1. 
Figura 1. Palitos formando ângulo nulo

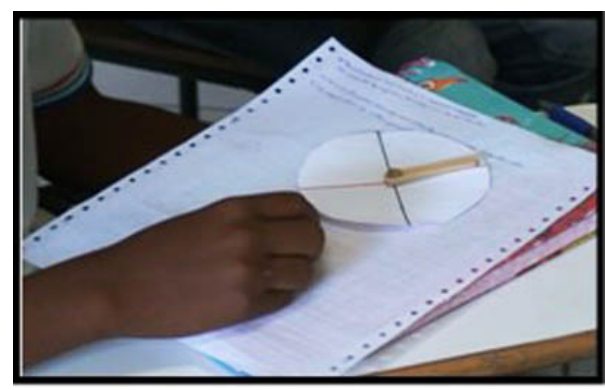

Fonte: arquivo dos autores.

A seguir, um recorte da transcrição que evidencia o momento no qual os estudantes concluíram que os palitos justapostos sugeriam um ângulo nulo:

(O1) Professora: Palitos posicionados... Existe ângulo nesse caso?

(O2) Marta: Existe...

(O3) Camila: Sim, tem ângulo...

(O4) Gabriela: [Risos]

(O5) Professora: De quanto é?

(O6) Professora: Nulo... De 0 grau!

(O7) Professora: Eu perguntei se existe ângulo... Então, caso exista, qual a medida dele?

(O8) Camila: 0 grau.

(O9) Professora: E como podemos nomeá-lo?

Ao perceber que eles já estavam se adiantando, a professora solicitou que posicionassem os palitos um em cima do outro, na posição inicial ${ }^{11}$. Ao mesmo tempo, ela indicava como deveria ser feito, a partir de outro manipulável. Desse modo, ela fez o movimento e perguntou aos estudantes qual ângulo teria sido formado (linha O1). Marta, linha (O2), reconheceu que ali se formou um ângulo, o que, aliás, acrescentou elementos à prática, como a noção de ângulo e a ideia de ângulo naquela posição especificamente. Os estudantes não só se engajaram na situação particular de reconhecer a posição dos palitos (segmentos de reta) formando ângulo nulo, ou seja, que existia um ângulo, mas também permitiram que outra situação se estruturasse naquele momento: qual medida teria tal ângulo.

\footnotetext{
${ }^{11}$ Termo utilizado pela professora para se referir à posição, na qual os palitos formavam ângulo nulo e não haviam sofrido nenhuma rotação.
} 
Camila (linha O3) concordou com Marta sobre a existência de um ângulo, mas só citou sua medida após os questionamentos da professora. Alguns estudantes disseram qual era o ângulo formado, outros não. Assim, mesmo que algum participante não soubesse a medida daquele ângulo, no momento em que ele foi exposto no grupo, esta medida passou a estar disponível para o grupo. Deste modo, a posição dos palitos determinando o ângulo nulo passou a ser parte da situação, a qual eles estavam experimentando conjuntamente. Como nenhum dos estudantes arriscou determinar o ângulo formado, a professora decidiu apontar e apresentar o ângulo nulo para eles (linhas O5 e O6).

A professora questionava-os na tentativa de incentivar os estudantes a formalizarem a compreensão sobre ângulo nulo, entendendo-o como ângulo em que a abertura entre os lados é nula, nomeando-o, assim, de ângulo nulo. Desse modo, neste episódio, compreendeu-se ângulo como uma abertura e, a partir da sobreposição dos palitos, foi possível, aos participantes, entenderem que ali era uma abertura nula. Sendo assim, os estudantes conseguiram não só compreender quando há um ângulo, como, também, o reconheceram como de 0 grau, além de nomeá-lo adequadamente.

Por conta disso, intitulamos esse episódio como "O engajamento na associação do ângulo nulo com a posição inicial dos palitos” no sentido de fazê-lo apresentar duas ideias básicas: reconhecer e compreender. Desse modo, foi apresentado o momento em que os participantes se focaram na tentativa de reconhecer o ângulo nulo, formado entre os palitos, e de compreendê-lo na posição em que se encontravam na situação. Além disso, os integrantes puderam associar a posição inicial ao ângulo nulo. Para isso, eles notaram que existia um ângulo quando os palitos estavam na posição inicial, ou seja, justapostos, e notaram que sua medida era de zero grau.

O engajamento consistiu no envolvimento que se moldou em torno de uma determinada situação, a de associar o ângulo nulo com a posição inicial. Nessa dinâmica, os estudantes envolveram-se numa negociação mútua de significados para os elementos que circunscreviam a situação. Tornaram-se engajados à medida que eram reconhecidos como participantes daquela situação, sintonizados com as falas, os afazeres e os manipuláveis ou seus elementos em questão. A discussão sobre os aspectos atrelados à posição inicial, a existência de um ângulo nessa posição e a medida deste ângulo poderia até figurar em outros momentos da aula, mas esse foi o momento mais incisivo, no qual os estudantes demonstraram um envolvimento com as peculiaridades do episódio.

\section{Episódio 2: $\mathrm{O}$ envolvimento de estudantes no recorte dos quadrados conforme as regras}

Inicialmente, foi possível observar que a professora definiu as regras inerentes à tarefa. Ou seja, ela apresentou como os estudantes poderiam proceder, deixando claro alguns limites e alguns casos em que eles teriam liberdade para decidir. Os estudantes receberam um kit de material (Figura 2) contendo tesouras sem ponta, três quadrados e um triângulo retângulo. A tarefa consistia na manipulação desses elementos, para que, de alguma maneira, surgissem entendimentos ou compreensões, por meio da prática do Teorema de Pitágoras e da sobreposição de áreas de figuras quadradas. Há uma forte presença da manifestação da professora, pois, nesta etapa, era necessário deixar as regras claras e os procedimentos adequados, além da orientação sobre a possibilidade de cortar o material, pois ele era feito de papel duplex. Vejam a Figura 2. 
Figura 2. Quadrados e triângulo retângulo

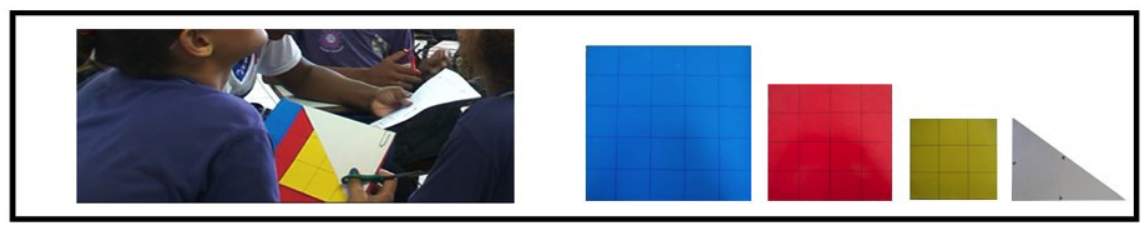

Fonte: arquivo dos autores.

A euforia e ansiedade dos estudantes exprimidas nos questionamentos frequentes “o que fazer?” e "como fazer?” - oportunizaram a apresentação dos materiais manipuláveis. Inicialmente, isso funcionou como um convite para a tarefa, como podemos ver abaixo:

(O1) Professora: O que é que a gente vai fazer... Não é? Todo mundo já leu o texto ai do início, não é?

(O2) Professora: Caro estudante, de posse do material... Que não é emborrachado, vocês tão vendo que é cartolina, então pode ser cortado livremente... Siga as orientações abaixo. (O3) Professora: Recorte os quadrinhos amarelos e vermelhos. [Os estudantes estão experimentando a tesoura e tocando os dois quadrados.]

(O4) João: Pode comecar a cortar Lucas. [Ele toma a frente com a tesoura, mas não começa a cortar os quadrinhos.]

(O5) Professora: Como está na tarefa... O azul não é para cortar. [Refere-se ao fato de que na folha de tarefa não constava instruções para cortar o azul.] (O6) Raquel: Toma. [Refere-se ao João e entrega uma tesoura a ele.]

(O7) João: Corta direito! [Falando com o Lucas.]

(O8) Flávia: É para cortar assim, não é? [Apontando para as linhas do quadrado amarelo.]

Como pode ser visto na linha O1, a professora iniciou as explanações referentes aos materiais ou a tarefa em foco. Nessa etapa, ela utilizou supressão de ideias para deixar os estudantes inquietos sobre o que fazer ou como se quisesse instigá-los a descobrir o que vem depois. Nas linhas O1, O2 e O3, a professora forneceu algumas orientações e frisou o fato de o material poder ser cortado, pois ele é feito de um material mais barato que o EVA. Com isso, com a ênfase de João, na linha O4, os estudantes tomaram fôlego e começaram a cortar. No entanto, apenas as meninas, de fato, começaram a cortar os quadrados. Raquel, após ter cortado uma tira do quadrado vermelho, passou a tira para João terminar o corte das unidades quadradas ${ }^{12}$ (linha O6). Raquel iniciou a tarefa muito quieta e reservada, mas, aos poucos, foi deixando-se levar pelas ações dos grupos e passou a contribuir mais incisiva e diretamente no trabalho. $\mathrm{Na}$ linha $\mathrm{O} 7$, João preocupou-se com o corte correto quando percebeu que Flávia iria cortar fora da linha no quadrado amarelo. 
Diante disso, vemos que esse entrelaçamento das linhas transcritas e discussões acerca destas linhas caracterizam o episódio intitulado "O envolvimento de estudantes no recorte dos quadrados conforme as regras", que fomenta o primeiro contato do grupo de estudantes observados com os materiais. Nesse momento, eles puderam: perceber as características dos materiais manipuláveis, notar coloridos diferentes, perceber as linhas cortando cada quadrado, observar as medidas de cada lado do triângulo, perceber a funcionalidade de cada elemento do material etc. É importante observar que, mesmo que alguns estudantes não tenham ficado com a tesoura em mãos, eles estavam envolvidos na tarefa de cortar os quadrados. O questionamento de um participante, não respondido, mostra a sintonia do grupo em relação às regras de corte. Todos apresentavam um grau de envolvimento suficiente, seja ele fiscalizando ou recortando, de acordo com a teoria. Portanto, eles se engajaram ao comecarem a cortar os quadrados e compreenderam a importância do corte adequado.

\section{Episódio 3: O envolvimento na associação dos lados dos quadrados com os lados do triângulo}

Neste episódio, os participantes encontravam-se no momento em que tiveram de compreender qual seria a relação dos quadrados com o triângulo retângulo em uma tarefa destinada a gerar compreensões sobre o teorema de Pitágoras a partir da manipulação dos materiais manipuláveis. Além disso, a obtenção da fórmula de tal teorema a partir da manipulação de elementos de um kit de figuras geométricas: quadrado amarelo, $15 \mathrm{~cm}$ de lado; quadrado azul, $25 \mathrm{~cm}$; quadrado vermelho, $20 \mathrm{~cm}$ de lado, e triângulo retângulo, com hipotenusa igual a $25 \mathrm{~cm}$, e catetos iguais a $4 \mathrm{~cm}$ e $3 \mathrm{~cm}$ (Ver a Figura 3).

Figura 3. Quadrados

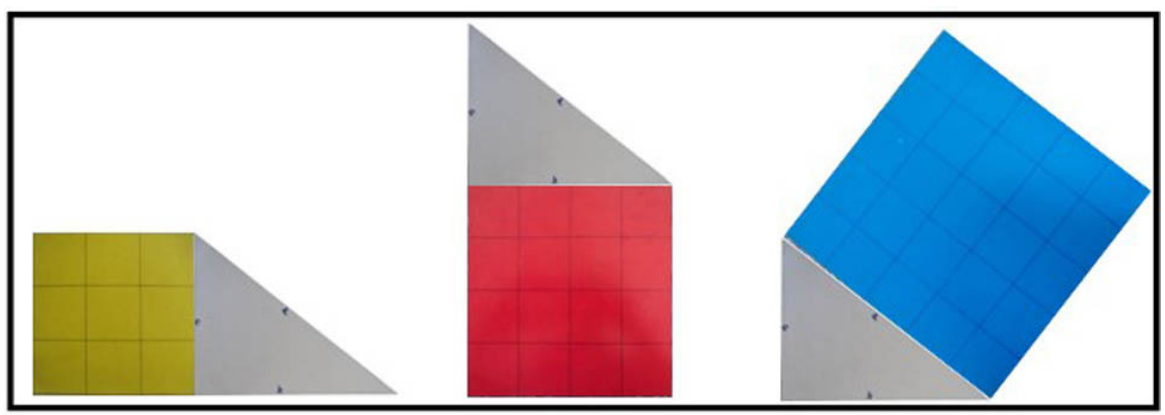

Fonte: arquivos dos autores.

\footnotetext{
${ }^{12}$ Usaremos, por vezes, a expressão unidades quadradas para representar os menores quadrados obtidos do corte, quadrados de $5 \mathrm{~cm}$ de lado.
} 
Nessa etapa, os estudantes tentaram remontar os quadrados cortados a priori, para que pudessem perceber as áreas destes e sua relação com os lados do triângulo. Vejam abaixo algumas discussões sobre isso:

(O1) João: Aqui gente, triângulo... lados, altura... [Aponta para o triângulo, tangenciando seu dedo como se desenhasse o perímetro do triângulo, além de apontar a altura do triângulo e do quadrado.]

(O2) Professora: A gente já conhece esses lados, não é Fernando?

(O3) Fernando: É o cateto...

(O4) Professora: Onde é cateto?

(O5) Fernando: Aqui. [Apontando para a hipotenusa do triângulo.]

(O6) Professora: Ai é cateto?

(O7) Fernando: Não... aqui, pró!

(O8) Professora: Agora vem cá, e esse daqui, esse azul, é de que lado do triângulo?

(O9) João: Hipotenusa!

(O10) Professora: Você acha que é hipotenusa?

(O11) João: Sim... é a hipotenusa mesmo.

$\mathrm{Na}$ linha O1, João demonstrou ter percebido alguns elementos geométricos presentes no material manipulável. Enquanto, nas linhas O2, O3 e O4 e O5, ele mostrou reconhecer alguma relação do lado do quadrado amarelo com o cateto do triângulo, mesmo que ele não saiba determinar onde se encontra o cateto (linhas O5 e O6).

Para o quadrado azul, eles conseguiram fazer uma referência mais imediata com a hipotenusa, talvez por este possuir um lado maior que os outros e lembrar a hipotenusa do triângulo, por esta ser o maior lado do triângulo, linhas O8 e O9. Os estudantes conseguiram compreender algumas relações quanto aos lados, partindo, posteriormente, para as relações quanto às áreas, como veremos a seguir:

(O13) João: Entendi... Está quase completo...

(O14) João: Vai cobrir tudo, entendi!

(O15) João: É porque a soma dos catetos... Não... É isso... A soma dos catetosé igual ao cateto maior, no caso hipotenusa.

(O16) Lucas: O quadrado é igual à hipotenusa... [Referindo-se à área do quadrado azul.]

(O17) Professora: Como é? O quadrado...? Igual a bipotenusa?

(O18) Fernando: Está. E o triângulo?

(O19) João: $A$ área dele...

(O20) Fernando: Professora! Professora...! A área do triângulo retângulo é igual à área do quadrado.

(O21) Professora: É isso? A área do triângulo retângulo é igual à área do quadrado? A gente conversou sobre área não foi?

(O22) Professora: Isso daqui é o triângulo. [Toma o triângulo em mãos e o faz sobrepor o quadrado.]

(O23) Professora: Ai, ele ocupa o quadrado? 
Os estudantes começaram a preencher a área do quadrado azul com as unidades quadradas vermelhas e amarelas (linhas O13 e O14), sobrepondo cada unidade quadrada vermelha e amarela nas unidades quadradas azuis. Nas linhas O14, O15 e O16, é possível notar que os estudantes estavam confundindo cateto com área. Nesse caso, eles acreditaram que os dois catetos eram iguais à hipotenusa. Talvez pelo fato de os quadrados (vermelho e amarelo) possuírem lados iguais aos catetos do triângulo retângulo, e suas áreas somadas serem iguais à área do quadrado azul, de lado igual à hipotenusa.

$\mathrm{Na}$ linha O16, por exemplo, Lucas dá indícios de um possível amadurecimento em termos de perceber a relação. Ele tentou relacionar o quadrado azul com a hipotenusa do triângulo, mas ele gesticulava como se quisesse falar da área e, ao mesmo tempo, apontava o lado do quadrado azul. Deste modo, ele deixou margens a futuras conclusões próprias ou de algum outro participante, e apontou a relação direta entre a hipotenusa e a área do quadrado (Esta relação pode ser sintetizada pela expressão hipotenusa x hipotenusa).

$\mathrm{Na}$ linha O18, Fernando preocupou-se com o triângulo e quais as relações teriam para ele de fato. Nesse momento, os estudantes se inspiraram e começaram a utilizar, frequentemente, o termo área. No entanto, eles acreditavam que a área do triângulo retângulo era igual à área do quadrado azul (linha O20). Lúcia questionou-os sobre tal afirmação nas linhas O21, $\mathrm{O} 22$ e O23 e eles chegaram à conclusão de que isso não era coerente apenas sinalizando com a cabeça. É importante salientar que todas as discussões foram feitas tendo o material em mãos.

Nesse caso, foram apresentadas e discutidas as relações dos quadrados com os lados do triângulo. Além disso, deu indícios de envolvimento dos participantes nessas situações, ou seja, nos momentos em que eles estavam se envolvendo em situações que se referem a tais relações, a sintonia e plenitude de tal engajamento está na forma como negociam conjuntamente os significados. Cada membro tem voz sobre determinados lados, relações entre esses ou, até mesmo, suas medidas, e sua fala pode ser incorporada ao fazer da prática ou não, isto é, negociação de significados. Com isso, podemos enfatizar que os estudantes se envolveram no reconhecimento de elementos geométricos no material manipulável, quando apontaram altura, lado, triângulo e quadrado; quando relacionam os lados do quadrado com os lados do triângulo; e quando eles tentaram expressar a área do quadrado em função do lado do triângulo. Esses momentos de engajamento caracterizam o episódio maior, dotado de início, meio e fim, mas que não são estáticos. Conforme discutem Lave e Wenger (1991), esse engajamento é imprescindível a uma prática social, em outras palavras, essa prática educacional se solidificou por meio do engajamento dispensado.

\section{Discussão dos dados e conclusões}

Neste artigo, discutimos como os participantes se engajam em determinadas situações sociais, por meio da observação de aulas de Matemática que abordaram o tópico de geometria, nas quais os participantes fizeram uso de materiais manipuláveis. Essa discussão teve a perspectiva da aprendizagem situada (LAVE; WENGER, 1991) como referencial teórico, que tem o engajamento mútuo como uma das três dimensões da prática social.

O fato de os estudantes participarem das aulas que abordaram o tópico geometria, ora se familiarizando com os manipuláveis, ora reconhecendo a relação dos quadrados com os lados do triângulo retângulo, ora compreendendo o ângulo nulo no círculo, caracterizou a participação 
nessa prática escolar. No entanto, essa participação não é comum a todas as práticas sociais e sugere formas diferentes de engajamento. De acordo com as ideias de Clements (1999) e Barbosa et al. (2008), os participantes progridem no sentido de se engajarem em diversas situações, experimentando, assim, diversas compreensões específicas proporcionadas pelo contexto. De todo modo, os estudantes estão sendo reconhecidos pelas suas ações, pelo seu modo de falar e por se engajarem de maneiras distintas (WENGER, 1998).

Assim, em conformidade com o objetivo do presente artigo, podemos notar que, no episódio intitulado "O engajamento na associação do ângulo nulo com a posição inicial dos palitos", os estudantes envolveram-se na descoberta do ângulo nulo, sem muitas orientações prévias da professora Ana, já que eles estavam se antecipando na tarefa. Os participantes compartilharam do saber atrelado à descoberta do ângulo nulo como posição inicial dos palitos. No entanto, a forma como eles tentaram determinar o ângulo nulo não foi compartilhada, isto é, eles mostram-se receosos para afirmar se existe ângulo ou não, e como poderia ser nomeado no caso dos palitos sobrepostos. Por isso, alguns deles até fizeram a rotação dos palitos sem maiores compreensões sobre os ângulos formados, enquanto outros apenas deixaram os palitos sobrepostos e na posição inicial.

O episódio intitulado "O envolvimento na associação dos lados dos quadrados com os lados do triângulo" sugere um envolvimento dos estudantes direcionado ao reconhecimento da relação: do quadrado amarelo com o cateto menor do triângulo retângulo (o lado $c$ ), do quadrado vermelho com o cateto médio (lado $b$ ) e do quadrado azul com a hipotenusa (lado a). Para cada participante engajar-se em tais descobertas, foi necessário não só o conhecimento de cada elemento associado à situação (seja a relação do quadrado amarelo, seja do vermelho ou do azul) por parte de cada participante, como, também, reconhecê-los de uma forma associada. Assim, os estudantes engajaram-se, mutuamente, num processo de visualizar tais relações. $\mathrm{O}$ processo de engajar-se, nesse sentido, se refere a ser ativo nos processos de negociação conjunta dos significados das relações possíveis entre o lado $c$ do quadrado amarelo e o menor lado do triângulo, também igual a $c$, bem como a relação entre o lado $b$ do quadrado vermelho e o lado médio do triângulo, também igual a $b$ e analogamente para o lado $a$.

Assim, envolver-se em torno de algo sempre está atrelado ao objetivo central, seja ele compreender o teorema de Pitágoras ou compreender os ângulos fundamentais a partir do círculo. Além disso, à medida que ocorre engajamento, ocorre, também, reconhecimento por parte de todos os participantes. Disso, decorrem duas dimensões: uns reconhecem explicitamente e outros não. Outro fator importante é a negociação de significados conjunta mediante cada engajamento. Isso é importante para demarcar que os significados atribuídos nessa atividade podem ter sentido apenas nessa situação. Por exemplo, o que é reconhecido como uma representação do círculo para outros pode ter outro significado que não este.

Quando os estudantes focalizam na obtenção e reconhecimento do ângulo nulo, eles envolvem-se numa situação também bastante particular da tarefa. A prática do grupo estava voltada para reconhecer aquela posição dos palitos como caracterizadora da angulação nula. Até os gestos, o balançar de cabeça favoreceram a negociação de significados, nesse caso. Por sinal, as ações da prática indicaram um dos muitos modos de se perceber o ângulo nulo. Em 
outras palavras, o modo especial de compreendê-lo, abstrair e tornar-se capaz de se valer da sua compreensão em outras ocasiões diferencia-se de outros modos, como ver o ângulo nulo apenas como um dos pontos de uma aula de Matemática que aborda o tópico geometria.

Os estudantes ganharam afinidade com os materiais manipuláveis gradativamente. João, por exemplo, envolveu-se no corte das unidades quadradas como se tivesse propriedade daquilo, - "Corta direito, Lucas" - reconhecendo e fazendo reconhecerem que o corte fora da linha poderia prejudicar o material ou, mesmo, sua compreensão. Assim, ao passo em que Flávia pergunta “Como?", também sugere uma sintonia com o que João falou na situação. Nesse sentido, tanto a visão de João atento para que se tivesse cuidado, quanto a forma correta do corte foram compartilhadas. De uma maneira ou de outra, cada estudante participou, seja argumentando ou, apenas, consentindo durante a situação.

Diante disso, concluímos que os estudantes podem apresentar diferentes modos de engajamento dentro de diferentes formas de participação, como já discutido acima, ao passo em que vão estabelecendo familiaridade com os manipuláveis ou reconhecendo ângulos e compreendendo o teorema de Pitágoras. Ao se engajarem na ação de reconhecer a representação do círculo como o próprio círculo, o que caracteriza uma tomada de decisão por parte dos participantes, os estudantes estão colocando em prática a negociação de significados das suas ações, interpretações e de suas argumentações.

Notamos, porém, que essas considerações são possíveis dentro de uma esfera local, mesmo que tenham poder expansivo e abranjam outras situações. De todo modo, acreditamos que podem existir outros modos de engajamento em outras esferas, até mesmo, a partir de outros olhares sobre essas. Assim, o engajamento mútuo proporcionado pelos materiais manipuláveis na aula de Matemática que abordou o tópico de geometria pode ter variações segundo o uso realizado pelo estudante.

Outra consideração importante diz respeito ao saber na prática. Nesse sentido, o saber ou conhecimento na prática está relacionado com o engajamento. Em outras palavras, conhecimento é uma questão de participação nesses modos de se engajar ativamente no mundo de uma maneira mais geral (WENGER, 1998), pois o saber dependeu intrinsecamente das relações estabelecidas, entre as pessoas, pertencentes à prática. Também notamos que esse saber é mutável seguindo parâmetros estabelecidos pela mudança na forma de engajamento mútuo.

Proença e Pirola (2011), por exemplo, apontam a importância da apresentação de figuras de triângulos com tamanhos diferentes aos estudantes, para que eles percebam que se trata da mesma figura. Semelhantemente, os participantes do grupo observado puderam experimentar formas diferenciadas de engajamento, seja reconhecendo algum ângulo, percebendo a existência de outro ou associando elementos geométricos.

Diante disso, conforme os resultados nesta pesquisa e consoante as compreensões geradas por outras pesquisas relacionadas direta ou indiretamente, acreditamos estar contribuindo com a compreensão sobre como funcionam outras formas de engajamento não destacadas aqui ou, até mesmo, em outras práticas sociais. Além disso, as implicações deste artigo podem gerar subsídios para compreendermos o fenômeno aprendizagem de estudantes. Possivelmente, estaremos também contribuindo com a reflexão acerca do trabalho em sala de aula. 


\section{Referências}

ALVES-MAZZOTTTI, A. J. O método nas ciências sociais. In: ALVES-MAZZOTTI, A. J.; GEWAMDSZNADJDER, F. O método nas ciências naturais e sociais: pesquisa quantitativa e qualitativa. São Paulo: Pioneira, 2002. p. 147-178.

BARBOSA, P. M. et al. A importância do pensamento visual na geometria. In: SEMINÁRIO DE PESQUISA EM EDUCAÇÃO MATEMÁTICA DO ESTADO DO RIO DE JANEIRO, 4., 2008, Rio de Janeiro. Anais... Rio de Janeiro: SBEM, 2008. p. 1-11.

CHARMAZ, K. Constructing grounded theory: a practical guide through qualitative analysis. London: Sage, 2009.

CLEMENTS, D. H. 'Concrete' manipulatives, concrete ideas. Contemporary Issues in Early Childhood, London, v. 1, n. 1, p. 45-60, 1999. Disponível em: <http:/ / cie.sagepub. com/content/1/1/45.full.pdf+html>. Acesso em: 13 nov. 2015.

DENZIN, N. K.; LINCOLN, Y. S. Introduction: the discipline and practice of qualitative research. In: . (Ed.) Handbook of qualitative research. 3. ed. Thousand Oaks: Sage, 2005. p. 1-32.

FRADE, C. Componentes tácitos e explícitos do conhecimento matemático de áreas e medidas. 2003. 251 f. Tese (Doutorado em Educação) - Faculdade de Educação, Universidade Federal de Minas Gerais, Belo Horizonte, 2003.

GELLERT, U. Didactic material confronted with the concept of mathematical literacy. Educational Studies in Mathematics, Dordrecht, v. 55, n. 1, p.163-179, 2004.

LAVE, J.; WENGER, E. Situated learning: legitimate peripheral participation. New York: Cambridge University Press, 1991.

LORENZATO, S. Laboratório de ensino de matemática e materiais didáticos manipuláveis. In: _. (Org.) O laboratório de ensino de matemática na formação de professores. São Paulo: Autores Associados, 2006. p. 3-38.

MOYER, P. S. Are we having fun yet? How teachers use manipulatives to teach mathematics. Educational Studies in Mathematics, Dordrecht, v. 47, n. 2, p.175-197, 2001.

NACARATO, A. M. Eu trabalho primeiro no concreto. Revista de Educação Matemática, São Paulo, v. 9, n. 9-10, p. 1- 6, 2005.

PAIS, L. C. Uma análise do significado da utilização de recursos didáticos no ensino da geometria. In: REUNIÃO NACIONAL DA ASSOCIAÇÃO NACIONAL DE PÓSGRADUAÇÃO E PESQUISA EM EDUCAÇÃO, 23., 2000, Caxambu. Anais... Disponível em: <http://23reuniao.anped.org.br/textos/1919t.PDF>. Acesso em: 13 nov. 2015.

PAULA, M. R. B.; SANZ ESPINAR, G. Coleta, transcrição e análise de produções orais.

Letras, Santa Maria, n. 21, p. 69-84, 2002. Disponível em: < http:/ / cascavel.ufsm.br/ revistas/ojs-2.2.2/index.php/letras/article/view/11529/6989>. Acesso em: 13 nov. 2015. 
PROENÇA, M. C.; PIROLA, N. A. O conhecimento de polígonos e poliedros: uma análise do desempenho de aluno do ensino médio em exemplos e não-exemplos. Ciência e Educação, Bauru, v. 17, n. 1, p. 199-217, 2011. Disponível em: < http://dx.doi. org/10.1590/S1516-73132011000100013>. Acesso em: 13 nov. 2015.

REMILLARD, J. T. Examining key concepts in research on teachers' use of mathematics curricula. Review of Educational Research, Berkeley, v. 75, n. 2, p. 211-246, 2005.

SILVA, M. C. F. Pausas em textos orais e espontâneos e em textos falados. Linguagem em Discurso, Tubarão, v. 3, n. 1, p. 111-133, 2002.

SOUZA, J. V. B.; BARBOSA, J. C. Os manipuláveis e a prática questionadora dos alunos na sala de aula de matemática. In: ENCONTRO NACIONAL DE EDUCAÇÃO MATEMÁTICA, 10., 2010, Salvador. Anais... São Paulo: SBEM, 2010. p.1-10. Disponível em: < http://www.lematec.net/CDS/ENEM10/artigos/CC/T20_CC716.pdf>. Acesso em: 13 nov. 2015.

WENGER, E. Comunities of pratices learning, meaning, and identity. Cambridge: Cambridge University Press, 1998. 